\title{
Comparing twice versus four times daily insulin in mothers with gestational diabetes in Pakistan and its implications
}

\author{
Nazish Saleem, FCPS ${ }^{1}$, Brian Godman, BSC, $\mathrm{PhD}^{2,3^{*}}$, Shahzad Hussain, $\mathrm{PhD}^{4}$ \\ ${ }^{1}$ Holy Family Hospital, Rawalpindi, Pakistan. Email: docnzish@hotmail.com \\ 2Department of Laboratory Medicine, Division of Clinical Pharmacology, Karolinska Institute, \\ Karolinska University Hospital Huddinge, SE-141 86, Stockholm, Sweden. Email: \\ Brian.Godman@ki.se \\ ${ }^{3}$ Strathclyde Institute of Pharmacy and Biomedical Sciences, Strathclyde University, Glasgow G4 \\ ORE, UK. Email: brian.godman@strath.ac.uk \\ ${ }^{4}$ National Institute of Health, Islamabad, Pakistan. Email: shahzadpharmacist1962@gmail.com
}

\begin{abstract}
*Author for correspondence: Brian Godman, Strathclyde Institute of Pharmacy and Biomedical Sciences, University of Strathclyde, Glasgow G4 ORE, United Kingdom. Email: brian.godman@strath.ac.uk. Telephone: 0141548 3825. Fax: 01415522562 and Division of Clinical Pharmacology, Karolinska Institute, Karolinska University Hospital Huddinge, SE-141 86, Stockholm, Sweden. Email: Brian.Godman@ki.se. Telephone + 468 58581068. Fax + 468 59581070
\end{abstract}

KEY WORDS: Gestational age, insulin, Gestational diabetes mellitus, fetal and maternal outcomes, Pakistan

(Accepted for publication Journal of Comparative Effectiveness - Please keep Confidential)

\section{ABSTRACT:}

Background: Gestational diabetes mellitus (GDM) is a common medical problem associated with maternal and fetal complications. Good glycaemic control is the cornerstone of treatment. Objective: Compare outcomes between four times $(4 x)$ and twice daily $(2 x)$ regimens. The morning dose of the $2 x$ regimen contained two thirds of the total insulin comprising one third human regular insulin and two thirds human intermediate insulin; equal amounts in the evening. Methods: 480 women at $>30$ weeks with GDM with failure to control blood glucose randomly assigned to either regimen. Results: Mean time to control of blood glucose significantly less and glycaemic control significantly increased with $4 \mathrm{x}$ regimen. Operative deliveries, extent of neonatal hypoglycaemia, babies with low Agpar scores and those with hyperbilirubinaemia significantly higher in $2 x$ daily regimen. Conclusion: $4 x$ daily regime associated with improved fetal and maternal outcomes. Consequently should increasingly be used in Pakistan, assisted by lower acquisition costs.

\section{INTRODUCTION}

Gestational diabetes mellitus (GDM) is defined as glucose intolerance during pregnancy. In most women who develop GDM, onset begins in the third trimester of pregnancy. Studies have recorded an incidence between 2 to $5 \%$ of pregnancies in the UK, with its prevalence rising (1). A recent study conducted in Pakistan found a lower prevalence at $<1 \%$ of pregnancies. In this study the mean Body Mass Index (BMI) and age were $24 \mathrm{~kg} / \mathrm{m} 2$ and 22 years respectively, and all women were primigravidae (2). However an earlier study by Akhter et al showed a higher prevalence at 3.3\% among Pakistani women (3). Rates in the US appear higher, with GDM seen among $8-9 \%$ of all pregnancies, with rates potentially doubling in populations at high-risk for type 2 diabetes (4). The highest prevalence of mothers with GDM are seen among South Asian and black Caribbean mothers, reaching up to $14 \%(5,6)$.

The National Institute for Health and Care Excellence in the UK currently recommends that women with potential risk factors including glycosuria, age $>30$ years, obesity, past history of GDM or glucose intolerance, or belonging to an ethnic group at high risk of GDM, be offered testing for GDM in the form of an oral glucose tolerance test (7). 
The International Association of Diabetes and Pregnancy Study Groups (IADPSG) recommends using a "one-step" 75-gram OGTT to diagnose GDM $(8,9)$ :
- $\quad$ TIME
- PLASMA GLUCOSE*
- Fasting
- $\quad \geq 92 \mathrm{mg} / \mathrm{dl}(5.1 \mathrm{mmol} / \mathrm{L})$
- 1-hour
- $\quad \geq 180 \mathrm{mg} / \mathrm{dl}(10.0 \mathrm{mmol} / \mathrm{L})$
- 2-hour
- $\quad \geq 153 \mathrm{mg} / \mathrm{dl}(8.5 \mathrm{mmol} / \mathrm{L})$

The principal features of foetal and neonatal complications in pregnant women with GDM are macrosomia, neonatal hypoglycaemia, perinatal mortality, congenital malformations, pyperbilirubinaemia, polycythemia, hypocalcaemia and respiratory distress syndrome (RDS) in the newborn, marked by dyspnea with cyanosis. RDS usually occurs in newborn babies who are pre-term, have diabetic mothers and who are delivered by caesarean section. However, sometimes there are no apparent predisposing causes (10-13). Maternal complications include hypertension, preeclampsia, and an increased risk of a lower (uterine) segment Caesarean section (LSCS) (14-16). Hypoglycaemia should be avoided as it can cause shakiness, nervousness, sweating, chills, irritability, confusion including delirium, rapid heart beats ,hunger and nausea, headache, fatigue, anger, nightmares, seizures and potentially unconsciousness.

Attempts to normalize blood glucose concentrations in pregnant mothers with GDM has become the cornerstone of treatment, with intensification of glucose monitoring as well as insulin administration improving perinatal outcomes $(17,18)$.

No differences in neurodevelopmental outcome were seen in 2-year-old children born to mothers with GDM treated with insulin or metformin during pregnancy (19). Most prospective trials involving insulin therapy in women with GDM have also shown a reduction in the incidence of neonatal macrosomia $(17,20,21)$. Mothers diagnosed with GDM should also have their blood pressure regularly monitored, undertake exercise and undergo nutrition counselling to help maintain normal glycaemia levels. In patients with well controlled diabetes, there is no need to expedite delivery before 40 weeks of gestation. In mothers who require insulin, or have other comorbid conditions, it is appropriate to begin antenatal screening with a non stress test and an amniotic fluid index at 32 weeks gestation.

With respect to insulin therapy, our impression is that an insulin regimen administered four times a day is neither complicated nor more expensive, and may provide better outcomes for mothers and babies, compared to twice daily regimens. In addition, may cost less. Such studies have been undertaken by other researchers in other countries $\mathrm{i}(22,23)$. However, we wanted to research this among a population in Pakistan since to the best of our knowledge such research has not been undertaken in this country before. Consequently, the objective of this study is to compare foetal and maternal outcomes of mothers with GDM receiving twice daily versus four times daily insulin regimen when diet and exercise had failed to control blood glucose levels over one to two weeks. Subsequently use the findings to provide future direction to key stakeholder groups in Pakistan.

\section{METHODOLOGY}

This quasi experimental study was conducted prospectively from June 2014 to September 2015 in the Obstetric ward at Holy Family hospital, Rawalpindi, Pakistan. The Holy Family hospital is the biggest hospital in the region serving a population of 5 million for ante natal care, and undertaking approximately 100-150 deliveries daily. 
We calculated based on previous studies, coupled with the limitation of only conducting this study in a single hospital and an envisaged informed consent rate of approximately $50 \%$, that we needed to approach 1000 mothers with GDM meeting the inclusion criteria for their consent to take part in the study..

Inclusion criteria included a singleton gestation and gestational age of 30 weeks or above. Random blood glucose testing (RBG) as well as fasting blood glucose (FBG) levels were subsequently used to help diagnose GDM. GDM was determined as follows: $100 \mathrm{~g}$ oral glucose ingestion followed by at least two serum glucose concentration values equal to or above 5.9,10.6, $9.2,8.1 \mathrm{mmol} / \mathrm{l}$ at $0,1,2$ and three hours respectively, or by the $75 \mathrm{gm}$ oral glucose tolerance test using the IADPSG criteria for diagnosis of GDM - the one step $75 \mathrm{gm}$ OGTT $(8,9)$ - with similar levels at fasting and two hours. Additional tests included glycosuria (++) on urine examination, abnormal glycosylated haemoglobin $(>6.1 \%)$ and booked as well as non-booked patients.

Mothers with congenital anomalies of their foetus and having other medical disorders including pre - existing diabetes were excluded from this study.

After informed consent, the mother's history was taken, This included their age, parity, gestational age, and the presence of any other associated maternal diseases. There was also a general physical examination, which included their blood pressure, pulse, temperature, and respiratory rate. The abdominal examination included the fundal height, lie of the foetus and its presentation as well as the foetal heart sounds.

Details regarding the mother's complete blood picture, chemistry, fasting blood glucose, two hours postprandial, two hours post lunch, two hours post dinner, urinalysis and $\mathrm{HbA1C}$ levels were also obtained prior to delivery. Foetal monitoring was carried out via a foetal kick count chart. There were also serial ultrasounds scans to determine the extent of foetal growth. A biophysical Profile and an amniotic fluid index score were also performed. Severe maternal hypoglycoemia was particularly noted.

The main foetal outcome measures were Apgar scores at 0 and 5 minutes, presence of hypoglycaemia, extent of glycaemic control, presence of hyperbilirubinemia and birth weight. The main maternal outcome measures included hypoglycaemia, extent of glycaemic control, mean time taken in both regimens to control blood glucose level and the extent of operative deliveries.

\section{Insulin regime and dietary recommendations}

Mothers who failed to have their blood glucose levels controlled on diet and exercise were randomly assigned to receive either the twice daily or four times daily insulin regimen by means of a computer generated random table.

For mothers allocated to the twice daily regimen, the morning dose contained two thirds of their total daily insulin with the afternoon dose the remainder. The morning dose comprised one third human regular insulin (Actrapid, Novo Nordisk) and two thirds human intermediate insulin (Insulated, Novo Nordisk), with the evening dose comprising equal amounts of regular and intermediate insulin.

Insulin was started with a minimum dose of 10 units. Adjustments to the insulin dose were subsequently individualized for the total amount of insulin as well as the ratios between the insulins according to the mothers' response,. For mothers allocated the four times daily insulin regimen, the first three doses of regular insulin were given by insulin pen (Novopen 3, Novo Nordisk) half an hour before each main meal, and the fourth dose of intermediate insulin was given before bed time. 
The dietary recommendations for all women were $0.13-0.15 \mathrm{MJ} / \mathrm{kg}$ of their ideal body weight, given as three meals and three snacks daily, comprising 55\% carbohydrate, $20 \%$ protein, and 25 $\%$ fat, with increased complex and decreased refined carbohydrates.

\section{Glycaemic control}

Glycaemic control was assessed by glucose monitoring and by monthly measurements of $\mathrm{HbA1C}$. Capillary whole blood glucose was measured by the glucose kinase methods when women were admitted to hospital and by self monitoring glucose reflectance meters at home (Accutrend, Accucheck). Values were verified by the glucometer's memory.

In both groups. six measurements were taken daily until adequate control was achieved. Thereafter, measurements were taken monthly for three months or until the baby was delivered. Goals for glycaemic control were blood glucose concentration of $3.5-5.9 \mathrm{mmol} / \mathrm{L}$ before meals (22), $6.7 \mathrm{mmol} / \mathrm{L}$ or less 2 hours after meals and mean daily values of $4.4-5.3 \mathrm{mmol} / \mathrm{L}$. The upper values served as the threshold for initiation of insulin or an increase of the dose. Mean glucose levels were calculated over an 11 hour period.

The aim for $\mathrm{HbA} 1 \mathrm{C}$ concentration was below $6 \%$. Hypoglycemia was characterised by abnormally low blood glucose levels $<70 \mathrm{mg} / \mathrm{dl}$, Severe maternal hypogycemia was characterized by blood glucose levels of $35-40 \mathrm{mg} / \mathrm{dl}$, and can lead to confusion, disorientation, convulsions, fitting , seizures, intense nightmares whilst asleep and loss of consciousness and coma. This typically requires assistance from another person to treat.

\section{Delivery}

An important objective was for the fetuses to be delivered at term. The timing of any induction of labour was determined by an overall assessment of maternal and fetal risk factors including poor compliance, suboptimal glycaemic control, vasculopathy, macrosomia, suspicious fetal biophysical test and a poor obstetric history. Patients with an uncomplicated GDM and an unfavourable cervix were allowed to await until spontaneous onset of labour. Delivery was induced if there was a favourable cervix at $38-41$ wks gestation or if the patient had not delivered by $41 \mathrm{wks}$. Treatment was individualised for those women with gestational diabetes whose pregnancy was complicated. The aim for glucose concentration was $4-5 \mathrm{mmol} / \mathrm{L}$ during labour and delivery.

At delivery, the neonate was attended by the neonatal staff with Agpar scores determined at 0 and 5 minutes. Blood samples were taken six times during the first day of life for measurement of plasma glucose concentration, and serum bilirubin was measured $1-3$ times from the first day of life. Serum bilirubin up till $1 \mathrm{mg} / \mathrm{dl}$ was seen as normal with random blood glucose levels uptil 40 $\mathrm{mg} / \mathrm{dl}$ seen as normal as well. If indicated, neonates were admitted to Neonatal ICU for dextrose infusion or phototherapy.

\section{Data Analysis}

All information collected was recorded in a pre - designed questionnaire. The data was entered on SPSS Version 10 for statistical analysis. Student's t-test was used to compare mean time taken to control blood glucose levels, Chi square test was used for glycaemic control, operative deliveries, Apgar Scores, birth weight, neonatal hypoglycaemia and hyperbilirubinaemia. Statistical significance was assigned to $p$-value $<0.05$. The variables studied included gestational age in weeks, mean time taken to control blood glucose levels, glycaemic control, mode of delivery and neonatal outcome such as Apgar Scores, birth weight, neonatal hypoglycaemia and hyperbilirubinaemia.

The study was approved by the bio-ethical committee (BEC) of the hospital and assigned protocol No. BEC-GAO-HFH-1134. 


\section{RESULTS}

480 mothers were eventually recruited equating to a $48 \%$ acceptance rate. 240 mothers with GDM subsequently received the twice daily insulin regimen and 240 received the four times insulin regimen.

The mean age of the mothers with GDM was $32+/-6$ years, with gestational ages more than 30 weeks (term pregnancies), The BMI of the mothers was between 29 and 35 . There were few primigravida with most mothers being mutipara having three or more children. Baseline glycemic levels were: fasting $>110 \mathrm{mg} / \mathrm{dl}$, post prandial $>140 \mathrm{mg} / \mathrm{dl}$ and baseline $\mathrm{HbA} 1 \mathrm{C}$ levels $>6.1 \%$. There were no significant differences in the case mix of the groups of mothers and in the frequency of background factors known to be associated with adverse outcome of pregnancy.

All were term pregnancies at more than 37 weeks of gestation with no premature deliveries. The mean mirth weight was $3.45 \mathrm{~kg}$ with no small for gestational age babies and no large for gestational age (LGA) babies. There was no macrosomia, no intrauterine deaths, no pregnancy induced hypertension (PIH) and no pre-eclampsia (PET).

The mean time interval to the control blood glucose levels is shown in Table 1. Overall, the mean time taken to control blood glucose levels was significantly less in patients who received the four times regimen compared to those who received twice daily insulin regimen ( $p=0.001$ - Table 1$)$.

Table 1: Mean time (hrs) taken to control blood glucose levels

\begin{tabular}{|l|c|c|c|c|c|}
\hline & Glycemic control & N & Mean & $\begin{array}{c}\text { Std. } \\
\text { Deviation }\end{array}$ & p value \\
\hline Mean time taken to \\
$\begin{array}{l}\text { control blood } \\
\text { glucose level }\end{array}$ & $\begin{array}{c}4.4-5.3 \text { mmol// } \\
\text { (four times regimen) }\end{array}$ & 192 & $6.500 \pm 0.33$ & $\begin{array}{c}1.6418 \\
+/- \\
0.3351\end{array}$ & \\
\cline { 2 - 5 } & $\begin{array}{c}\text { more than } 5.3 \\
\text { mmol/l } \\
\text { (twice daily regimen) }\end{array}$ & 288 & $9.694 \pm 0.37$ & $\begin{array}{c}2.2016 \\
+/- \\
0.3669\end{array}$ & \\
\hline
\end{tabular}

Glycemic control as reflected in the mean daily concentration of glucose (Table 2) was significantly better with the four times insulin regimen compared to the twice daily regimen $\mathrm{p}=0.001$ (Table 2). 176 mothers who received the four times regimen had better glycaemic control compared to only 16 mothers who received twice daily regimen ( $73.3 \%$ vs. $6.6 \%)$. In addition, only 64 mothers did not achieve glycaemic control in four times regimen compared with 184 with the twice daily regimen.

Table 2: Extent of Glycemic Control

\begin{tabular}{|l|l|c|c|c|c|c|c|c|c|}
\hline \multicolumn{2}{|c|}{} & 4 times & 2 times & Total & $\begin{array}{c}\mathbf{C h i}^{2} \\
\text { test }\end{array}$ & $\begin{array}{c}\mathbf{p} \\
\text { value }\end{array}$ & $\begin{array}{c}\text { likelihood } \\
\text { ratio }\end{array}$ & $\begin{array}{c}\mathbf{p} \\
\text { value }\end{array}$ & $\mathbf{d f}$ \\
\hline \multirow{2}{*}{$\begin{array}{l}\text { Glycemic } \\
\text { control }\end{array}$} & $4.4-5.3$ & 176 & 16 & 192 & 222.22 & 0.001 & 250.17 & 0.001 & 1 \\
\cline { 2 - 10 } & $>5.3$ & 64 & 224 & 288 & & & & & \\
\hline \multicolumn{2}{|l|}{ Column Total } & 240 & 240 & 480 & & & & & \\
\hline
\end{tabular}

A higher mean dose of insulin was given to mothers who received insulin four times daily; however, without an increase in episodes of severe maternal hypoglycemia. 192 patients in the four times regimen group had an episode of hypoglycemia during the course of the study compared to 80 patients in twice daily regimen group (p. 0.001 ) (Table 3$)$ - (80\% Vs $33.3 \%$ ). However, overall glycemic control was improved in the four times daily regimen group (Table 2 ). 
Table 3: Maternal Hypoglycemia

\begin{tabular}{|l|l|c|c|c|c|c|c|c|c|}
\hline \multicolumn{2}{|c|}{} & $\begin{array}{c}\mathbf{4} \\
\text { times }\end{array}$ & $\begin{array}{c}\mathbf{2} \\
\text { times }\end{array}$ & Total & Chi $^{2}$ test & $\begin{array}{c}\mathbf{p} \\
\text { value }\end{array}$ & $\begin{array}{c}\text { likelihood } \\
\text { ratio }\end{array}$ & $\begin{array}{c}\mathbf{p} \\
\text { value }\end{array}$ & df \\
\cline { 1 - 9 } $\begin{array}{l}\text { Maternal } \\
\text { Hypoglycemia }\end{array}$ & Yes & 192 & 80 & 272 & 106.43 & 0.001 & 111.14 & 0.001 & 1 \\
\cline { 2 - 10 } & No & 48 & 160 & 208 & & & & & \\
\hline
\end{tabular}

A statistical difference was found between the two groups regarding the method of delivery (Table 4 ) with 72 mothers in the four times daily regimen undergoing LSCS compared to 120 patients in twice daily regimen. However, there was no difference in the extent of pregnancy induced hypertension between the two insulin groups.

Table 4 - Mode of Delivery.

\begin{tabular}{|l|l|c|c|c|c|c|c|c|c|}
\hline \multicolumn{2}{|c|}{} & $\begin{array}{c}\mathbf{4} \\
\text { times }\end{array}$ & $\begin{array}{c}\mathbf{2} \\
\text { times }\end{array}$ & Total & Chi $^{2}$ test & $\begin{array}{c}\mathbf{p} \\
\text { value }\end{array}$ & $\begin{array}{c}\text { likelihood } \\
\text { ratio }\end{array}$ & p value & df \\
\hline \multirow{2}{*}{ MoD } & Svd & 168 & 104 & 272 & 43.06 & 0.001 & 49.51 & 0.001 & 2 \\
\cline { 2 - 6 } & Lscs & 72 & 120 & 192 & & & & & \\
\hline & inst & 0 & 16 & 16 & & & & & \\
\hline
\end{tabular}

NB: Svd = spontaneous vaginal delivery, Lscs $=$ Lower caesarean section and inst $=$ instrumental delivery

Among the women with GDM receiving the twice daily regimen, emergency caesarean sections were performed in $30 \%$ with $20 \%$ elective. The indications for elective caesarean sections were two or three previous scars.

Tables 5 to 7 summarize the neonatal outcome data. In neonates born to mothers with GDM, the most prevalent complications of hypoglycaemia and hyperbilirubinaemia were lower in neonates whose mothers received the four times daily regimen compared with twice daily regimen.

16 babies in the four times daily regimen group had hypoglycemia versus 136 in the twice daily regimen group hypoglycaemia(6.6\% Vs $56.6 \%)$, which was statistically significant $(p=0.001) .224$ neonates did not have hypoglycaemia in the four times daily regimen, compared with only 104 neonates in the twice daily regimen $(p=0.001)$ - Table 5 .

Table 5: The extent of hypoglycemia in neonates

\begin{tabular}{|l|c|c|c|c|c|c|c|c|c|}
\hline & & $\begin{array}{c}\mathbf{4} \\
\text { times }\end{array}$ & $\begin{array}{c}\mathbf{2} \\
\text { times }\end{array}$ & Total & Chi' $^{2}$ test & $\begin{array}{c}\mathbf{p} \\
\text { value }\end{array}$ & $\begin{array}{c}\text { likelihood } \\
\text { ratio }\end{array}$ & p value & df \\
\cline { 1 - 10 } Hypoglycaemia & $<40$ & 16 & 136 & 152 & 138.64 & 0.001 & 153.36 & 0.001 & 1 \\
\cline { 2 - 10 } & $>40$ & 224 & 104 & 328 & & & & & \\
\hline
\end{tabular}

40 neonates in the four times daily regimen group had hyperbilirubinaemia versus 136 in the twice daily group ( $16.6 \%$ Vs $56.6 \%)$, which was statistically significant $(p=0.001)$. 200 neonates did not have hyperbilirubinaemia in four times daily group compared to 104 in the twice daily regimen group $(p=0.001)$ - Table 6 . 
Table 6: Hyperbilirubinemia among neonates

\begin{tabular}{|l|c|c|c|c|c|c|c|c|c|}
\hline & & $\begin{array}{c}\mathbf{4} \\
\text { times }\end{array}$ & $\begin{array}{c}\mathbf{2} \\
\text { times }\end{array}$ & Total & $\begin{array}{c}\mathbf{C h i}^{\mathbf{2}} \\
\text { test }\end{array}$ & $\begin{array}{c}\mathbf{p} \\
\text { value }\end{array}$ & $\begin{array}{c}\text { likelihood } \\
\text { ratio }\end{array}$ & $\begin{array}{c}\mathbf{p} \\
\text { value }\end{array}$ & df \\
\hline \multirow{2}{*}{$\underline{\text { Hyperbilirubinemi }}$} & $>$ & 40 & 136 & 176 & 82.6 & 0.001 & 86.17 & 0.001 & 1 \\
\cline { 1 - 10 } & 1 & & & & 8 & & & & \\
\cline { 2 - 10 } & 1 & 200 & 104 & 304 & & & & & \\
\hline
\end{tabular}

There was a statistically significant difference in the Apgar scores (A/S) of neonates (Table 7) between the two regimens. 224 neonates in the four times daily regimen group had a A/S $>7$ / 10 versus 68 in twice daily regimen, which was statistically significant $(p=0.001) .16$ neonates in four times group had A/S $<7$ / 10 compared with 104 babies in twice daily group.

Table 7: Apgar Score of neonates

\begin{tabular}{|l|l|c|c|c|c|c|c|c|c|}
\hline & & $\begin{array}{c}\mathbf{4} \\
\text { times }\end{array}$ & $\begin{array}{c}\mathbf{2} \\
\text { times }\end{array}$ & Total & $\begin{array}{c}\mathbf{C h i}^{2} \\
\text { test }\end{array}$ & $\begin{array}{c}\mathbf{p} \\
\text { value }\end{array}$ & $\begin{array}{c}\text { likelihood } \\
\text { ratio }\end{array}$ & $\begin{array}{c}\mathbf{p} \\
\text { value }\end{array}$ & df \\
\cline { 1 - 9 } $\begin{array}{l}\text { Apgar Score } \\
\text { of Baby }\end{array}$ & $>7 / 10$ & 224 & 136 & 360 & 86.04 & 0.001 & 93.84 & 0.001 & 1 \\
\cline { 2 - 10 } & $<7 / 10$ & 16 & 104 & 120 & & & & & \\
\hline
\end{tabular}

There was no statistically significant difference in birth weight of babies born to mothers in either group, with an average weight of $3.4 \mathrm{~kg}+/-0.269 \mathrm{~kg}$.

\section{DISCUSSION:}

In this study, intensive blood glucose monitoring as well as various other factors were used to evaluate which of the two insulin dose regimen would provide better overall outcomes for both mothers and babies in mothers with GDM.

With respect to the babies born, mothers with GDM who received the four times daily insulin regimen had a significant reduction in the rate of neonatal hypoglycemia (6.6\% Vs $56.6 \%)-$ Table 5, and hyperbilirubinemia (16.6\% Vs $56.6 \%$ - Table 6 ) versus those mothers administering the twice daily regimen. The reduction in the rate of both hypoglycaemia and hyperbilirubinaemia among neonates resulted from the significant improvement in glycaemic control in mothers (73.3\% Vs 6.6\% - Table 2). This in turn resulted from an increase in the mean dose of insulin administered. Our findings are in agreement with those of others(24-27) who found that administrating the four times daily regimen in pregnancy improved glycaemic control and perinatal outcomes without risk to the mother except for hypoglycaemia. However, this did not lead to severe hypoglycaemia. In our study, women who received the four times daily regimen also had more episodes of hypoglycaemia (Table 3). However, glycemic control was improved in the four times regimen (Table 2), and overall there was no difference in the birth weight of infants with either regimen. This was in agreement with the study by Price et al (28), although contrasted with the findings of DeVeciana et al (29). These authors found that the four times daily regimen did lead to a further reduction in the incidence of large babies, i.e. with birth weights greater than $4 \mathrm{~kg}$ or a birth weight greater that the $90 \%$ centile.

Overall, this study showed that the four times daily regimen of insulin provided a significantly better outcome for mothers with GDM in terms of a significantly greater chance of a vaginal delivery, and a correspondingly lower chance of an instrumental delivery or LSCS (Table 4). Neonates also had significantly higher agpar scores and a significantly lower chance of hyperbilirubinaemia (Tables 6 and 7). The improvements in outcomes with the four times daily regimen is in agreement with the findings of Konje et al (22). The four times daily regimen was 
also marginally less expensive at 789PKR (US\$7.44) versus 799PKR (US\$7.53) for the twice daily regimen. In addition, the four times daily regimen contains only one type of insulin. This contrasts with the twice daily regimen where there are frequent changes in the ratio of each injection, which can be cumbersome for the patient. This finding is in agreement with the those of Nachum et al (24).

We are aware that our study was carried out within a single hospital in Pakistan. However, we believe that in view of the large number of mothers with GDM enrolled, and the highly significant results that we saw in a number of key maternal and foetal outcome parameters between the two regimes, that the findings should be applicable to other women with GDM in Pakistan. We are also planning further studies to substantiate the observations seen as well as look at different ratios of insulin in the twice daily regimen, e.g. 50:50, to see if our conclusions still hold.

\section{CONCLUSION}

The results of this study suggests that compared with the twice daily insulin regimen, the four times daily insulin regimen for GDM patients results in significantly improved fetal and maternal outcomes across a range of measures including reduced operative deliveries alongside improved Agpar scores of babies, neonatal hypoglycemia, and neonatal hyperbilirubinemia. The four times daily regimen may be associated with greater maternal hypoglycemia; however this was not severe enough to cause symptoms and overall glycemic control was significantly better with the four rimes daily regimen. As a result, the four times daily regime should increasingly be used in Pakistan, assisted by lower costs. We will be looking to substantiate this in future studies including future studies with different insulin ratios for the twice daily regimen.

\section{Summary points}

1. Gestational Diabetes Mellitus (GDM) is a common medical problem worldwide, with mothers from South Asia and black Caribbean women at particular risk with a prevalence up to $14 \%$ of all mothers

2. All women with risk factors for GDM should be offered 2- hours 75gm OGTT at 24-28 weeks of pregnancy. Women who have had GDM in a previous pregnancy should be screened much earlier at $16-18$ weeks.

3. Patients not meeting FBS $<95 \mathrm{mg} / \mathrm{dl}$ and $2 \mathrm{hrs}$ post prandial blood glucose levels $<120 \mathrm{mgdl}$ with dietary changes should begin insulin therapy.

4. Antenatal screening should begin in such patients at 32 weeks with non stress test(NST) and amniotic fluid index(AFI) with infants to be delivered at term.

5. Four times regimen results appears to be significantly better in terms of fetal and maternal outcomes across a range of measures as compared to a twice daily insulin regimen. These include the extent of maternal glycemic control, mode of delivery as well as the extent of hypoglycemia and hyperbilirubinemia in neonates and their Agpar scores.

\section{Acknowledgements, funding sources and conflicts of interest}

We strongly acknowledge the support of the mothers who participated in this study, along with physicians, staff attendants and the laboratory staff of the Holy Family hospital who gave their time and expertise to assist with this study. We also thank the hospital for providing the funds to procure the medicines for this study.

The write-up of this study was in part sponsored by the Karolinska Institutet. 
The authors declared they have no other conflicts of interest.

\section{REFERENCES:}

1. Dornhorst A, Williamson C. Diabetes \& endocrine disease in pregnancy. In: Edmond K.D. Dewhurst's Textbook of obstetrics \& gynaecology. $17^{\text {th }}$ edition. UK: Blackwell Publishing $2007 ; 246$

2. Jawa A, Raza F, Qamar K, Jawad A, Akram J. Gestational diabetes mellitus is rare in primigravida Pakistani women. Indian J Endocrinol Metab 2011; 15: 191-3.

3. Ahkter J, Qureshi R, Rahim F, Moosvi S, Rehman A, Jabbar A, et al. Diabetes in pregnancy in Pakistani women: prevalence and complications in an indigenous south Asian community. Diabet Med 1996; 13: 189-91.

4. DeSisto CL, Kim SY, Sharma AJ. Prevalence Estimates of Gestational Diabetes Mellitus in the United States, Pregnancy Risk Assessment Monitoring System (PRAMS), 2007-2010. Prev Chronic Dis, 11:130415, 2014

5. Report of the expert committee on the diagnosis and classification of diabetes mellitus. Diabetes care. 2003;26 Suppl 1:S5-20

6. American Diabetes Association. Gestational diabetes mellitus. Diabetes care. 2004;27 Suppl 1:S88-90

7. NICE clinical guideline no. 63. Diabetes and Pregnancy, July 2008. Available via URL: www.nice.org.uk/CG 63 \{accessed on 13th November, 2015\}

8. Metzger BE, Lowe LP, Dyer AR, Trimble ER, Chaovarindr U, Coustan DR, Hadden DR, McCance DR, Hod M, Mclntyre HD, oats JJ, Persson B, Rogers MS, Sacks DA. Hyperglycemia and adverse pregnancy outcomes. N Engl J Med, 358:1991-2002, 2008

9. Report of the Expert Committee on the Diagnosis and Classification of Diabetes Mellitus. Diabetes Care 37 (Suppl 1):S81-S90, 2014.(introduction)

10. Kim C, Newton KM, Knopp RH. Gestational diabetes and the incidence of type 2 diabetes: a systematic review. Diabetes Care 2002; 25:1862-8

11. Hanna FW, Peters JR. Screening for gestational diabetes; past, present and future. Diabet Med 2002; 19:589-93.

12. Wender-Ozegowska E, Wroblewska K, Zawiejska A, Pietryga M, Szczapa J, Biczysko R. Threshold values of maternal blood glucose in early diabetic pregnancy - prediction of fetal malformations. Acta obstet Gynecol Scand 2005; 84:17-25

13. Vaarasmaki M, Gissler M, Ritvanen A, Hartikainen AL. Congenital anomalies and first life year surveillance in Type 1 diabetic births. Diabet Med 2002; 19:589-9314. Mackenzie IZ. Diabetes in: James D, Steer JP. High risk pregnancy. $3^{\text {rd }}$ edition. UK: W.B. Saunder 1999; 987 15. NHS. Gestational diabetes - Complications. Available at URL:

http://www.nhs.uk/Conditions/gestational-diabetes/Pages/Complications.aspx (Accessd 2 May 2016)

16. Mayo Clinic. Diseases and Conditions - Gestational diabetes. Complications. Available at URL: http://www.mayoclinic.org/diseases-conditions/gestational-

diabetes/basics/complications/CON-20014854 (Accessed 2 May 2016)

17. Turok DK, Ratcliffe SD, Baxley EG. Management of Gestational Diabetes Mellitus. Am Fam Physicians 2003; 68:1767-72

18. Ito Y, Shibuya M, Hosokawa S, Motoki Y, Nagata R, Konishi H, Miyazaki T, Matsunaga T, Nomura Y, Mihara T, Ito S, Sugiura K, Terauchi Y. Indicators of the need for insulin treatment and the effect of treatment for gestational diabetes on pregnancy outcomes in Japan. Endocr J. 2015 Nov 25 [Epub ahead of print]

19. Tertti K, Eskola E, Rönnemaa T, Haataja L. Neurodevelopment of Two-Year-Old Children Exposed to Metformin and Insulin in Gestational Diabetes Mellitus. J Dev Behav Pediatr. 2015 Nov-Dec;36(9):752-7. doi: 10.1097/DBP.

20. Langer O, Conway DL, Berkus MD, Xenakis EM, Gonzales O. A comparison of glyburide and insulin in women with gestational diabetes mellitus. N Engl J Med. 2000;343:1134-8

21. Glueck CJ, Wang P, Goldenberg N, Sieve-Smith L. Pregnancy outcomesamong women with polycystic ovarian syndrome treated with metformin. Hum Reprod 2002;17:2858-64. 
22. Konje C.J .Diabetes Mellitus.In: Luesley M.D,Baker NP,Obstetrics and Gynaecology - an evidenced based text for MRCOG .1st edition .Great Britain :Arnold 2004;50.

23. Fulcher GR, Gilbert RE, Yue, DK. Glargine is superior to neutral protamine Hagedorn for improving glycated haemoglobin and fasting blood glucose levels during intensive insulin therapy. Intern Med J 2005; 35: 536-42.

24. Nachum Z, Ben - Shlomo I, Weiner E, Shalev E. Twice daily versus four time daily insulin dose regimen for diabetes and pregnancy: randomised controlled trail. BMJ 1999: 319: $1223-$ 1227.

25. Oats JJ, David-McIntyre HD. Revision of guidelines for the management of Gestational diabetes Mellitus. Med J Aust 2004;181:342

26. Tamas G, Kerenyi Z. Current controversies in the mechanisms and treatment of gestational diabetes. Curr Diab Rep 2002; 2:337-46.

27. Cohen ND, Shaw JE. Diabetes: advances in treatment. Intern Med J 2007; 37:383-8.

Yogev Y, Ben-Haroush A, Chen R, Rosenn B, Hod M, Langer O. Undiagnosed Asymptomatic Hypoglycemia: Diet, Insulin, and Glyburide for Gestational Diabetic Pregnancy. Obstet Gynecol 2004; 104: 88-93.

28. Price N, Bartlett C, Gillmer MD. Use of insulin glargine during pregnancy: a case - control pilot study. BJOG 2007; 114:453-457.

29. De Veciana M, Major CA, Morgan MA, Asrat T, Toohey JS, Lien JM, et al. Postprandial versus preprandial blood glucose monitoring in women with gestational diabetes mellitus requiring insulin therapy. $\mathrm{N}$ Engl J Med 1995; 333: 1237-41 